\title{
Study of the Effects of Modifying Additives \\ on the Properties of Nonstick Coating \\ for Iron and Steel Casting
}

\author{
Elena M. Lesiv*, Pavel O. Yuryev, \\ Sergey V. Belyaev, Vladimir N. Baranov, \\ Galina S. Sanacheva and Elena V. Rasskazova* \\ Siberian Federal University \\ 79 Svobodny, Krasnoyarsk, 660041, Russia
}

Received 10.02.2016, received in revised form 01.03.2016, accepted 13.03.2016

The paper presents results of the effect of muscovite as a modifying agent to mechanically activated bentonite clays of different fields. It modifying additive increasing the electrostatic characteristics of the aqueous suspensions based on them, in order to increase the stability of colloidal systems, used in nonstick coatings for production steel and iron casting.

Keywords: mechanoactivation, clay, muscovite, zeta-potential, polarization, electrostatic characteristics, montmorillonite.

Citation: Lesiv E.M., Yuryev P.O., Belyaev S.V., Baranov V.N., Sanacheva G.S., Rasskazova E.V. Study of the effects of modifying additives on the properties of nonstick coating for iron and steel casting, J. Sib. Fed. Univ. Eng. technol., 2016, 9(6), 933-943. DOI: 10.17516/1999-494X-2016-9-6-933-943.

(C) Siberian Federal University. All rights reserved

* Corresponding author E-mail address: emlesiv@inbox.ru 


\title{
Исследование влияния модифицирующей добавки \\ на свойства противопригарных покрытий \\ дЛя чугунного и стального литья
}

\author{
Е.М. Лесив, П.О. Юрьев, С.В. Беляев, \\ В.Н. Баранов, Г.С. Саначева, Е.В. Рассказова \\ Сибирский федеральный университет \\ Россия, 660041, Красноярск, пр. Свободный, 79
}

В статье приведены результаты влияния мусковита как модифицирующей добавки к механоактивированным бентонитовым глинам различных месторождений, повышаюшим электростатические характеристики водных суспензий на их основе для увеличения стабильности коллоидных систем, применяемых в противопригарных покрытиях для стального и чугунного литья.

Ключевые слова: механоактивация, глина, мусковит, дзета-потенциал, поляризованность, электростатические характеристики, монтмориллонит.

\section{Введение}

Бентонитовые глины относятся к важнейшим нерудным полезным ископаемым, широко используемым в различных отраслях промышленности, в особенности в литейном производстве. Они широко применяются вследствие того, что в жидкой среде легко распадаются на элементарные частицы, т.е. часть катионов отходит от поверхности глинистой частицы и образует катионную оболочку, которая представляет собой положительно заряженные обменные катионы, в основном $\mathrm{Na}, \mathrm{K}, \mathrm{Ca}, \mathrm{Mg}$. В результате нарушения молекулярных связей поверхность глинистой частицы оказывается заряженной отрицательно, а за счет замещения трехвалентных элементов $\mathrm{Al}, \mathrm{Fe}$ в среднем октаэдрическом слое на двухвалентные $(\mathrm{Mg}, \mathrm{Fe})$ или четырехвалентного $\mathrm{Si}$ - на трехвалентный $\mathrm{Al}$ в тетраэдрическом слое пакет суммарно несет отрицательный заряд [1]. В связи с процесами, происходящими с монтмориллонитовой глиной при контакте с водным растворителем, возникает необходимость их изучения с точки зрения электростатических взаимодействий образуемой коллоидной системы. Влияние времени механоактивации на электростатические характеристики (ЭСХ) монтмориллонитовых глин Таганского и Черногорского месторождений описаны в статьях [2-4] и составили 120 и 90 с соответственно в мельнице планетарно-центробежного типа Reatsch PM 400 MА при объемном соотношении материала к мелющим телам 1:1. Потом происходит агломерация и коагуляция частиц глинистого материала и, как следствие, снижение всех ЭСХ. Поэтому возникла необходимость проведения дополнительных исследований.

\section{Модифицирование формовочных глин мусковитом}

Для повышения ЭХС глин Таганского и Черногорского месторождений был выбран минерал из класса водных алюмосиликатов, группа слюд - мусковит. Химическая формула минерала $\mathrm{KAl}_{2}\left[\mathrm{AlSi}_{3} \mathrm{O}_{10}\right](\mathrm{OH})_{2}$. Основной элемент структуры мусковита - трёхслойный пакет, 
состоящий из двух кремнеалюмокислородных тетраэдрических слоёв и внутреннего октаэдрического слоя с двух- или трёхвалентными катионами $\mathrm{Mg}, \mathrm{K}, \mathrm{Ca}, \mathrm{Fe}, \mathrm{Al}$, поэтому он является породообразующим минералом, часто сопутствующим, с монтмориллонитовыми глинами на нижних пластах. В силу способности легко расщепляться на мелкие «листочки» и благодаря малому удельному весу он скапливается обычно в илистых осадках и слоистых глинах, образующихся в водных бассейнах при замедленном движении вод. В условиях интенсивного химического выветривания мусковит способен переходить в более богатые водой гидрослюды гидромусковиты, а при переходе в раствор щелочей - в каолинит [5].

Определение электростатических характеристик исходных глин проводилось на 5\%-х водных суспензиях. Прибор DT-310 позволяет выявить дзета-потенциал, поверхностный заряд, диаметр двойного электрического слоя, микровязкость объема суспензии, частоту МаксвеллаВагнера.

Поверхностный заряд и диаметр двойного электрического слоя - характеристики отдельной частицы, входящей в состав коллоидной системы. Этими двумя характеристиками определяется числовое значение дзета-потенциала, а также возможности протекания процессов агломерации и седиментации в системе относительно их численного значения.

Частота Максвелла-Вагнера характеризует электрическую поляризацию как накопление свободных зарядов на границах раздела фаз. Теория поляризации Максвелла-Вагнера в формальном отношении оказывается асимптотическим случаем общей электродиффузионной теории коллоидной системы. Данный параметр характеризует общую поляризованность системы, т.е. структурированность диполей воды (растворителя) относительно заряженных частиц материала (растворенного вещества).

В табл. 1 представлены ЭСХ суспензий глин Таганского месторождения в исходном и механоактивированном состояниях. Измерения ЭСХ проводили сразу после затворения 5\%-й суспензии и после после 24-часового отстоя. На рис. 1 и 2 даны значения дзета-потенциала для исследуемых материалов сразу после затворения водно-глинистой суспензии и после 24-часового отстоя.

Из данных табл. 1 видно, что дзета-потенциал с увеличением количества введенного мусковита в материал увеличивается с 20,11 до 24,01 мВ для суспензий без отстоя и с 28,32 до 30,36 мВ для суспензий с 24-часовым отстоем. Максимальное значение дзета-потенциала соответствует глинистому материалу, механоактивированному в течение 120 с, с 5 \% механоактивированного мусковита. Последующая механоактивация приводит к уменьшению данной характеристики до 15,87 мВ вследствие превалирования более тяжелых частиц мусковита, которые в течение времени свободно седиментируют.

Частицы, которые не сумели образовать электростатические связи в системе из-за их переизбытка, аккумулируют, образовав дополнительный заряд на поверхности (до 0,644 мВ для суспензии после 24-часового отстоя, с 4 \% мусковита в системе). Переизбыток частиц несет в себе дополнительное количество свободных положительных ионов $\mathrm{Na}, \mathrm{Ca}, \mathrm{Mg}$, которые остаются в диффузионном слое, способствуя процессу переориентации диполей воды, тем самым уменьшая общую поляризованность и структурированность диполей воды относительно отрицательно заряженной частицы глинопорошка. Начало этого процесса наблюдается при уменьшении максвелл-вагнеровской частоты для эксперимента с 4 \% мусковита в системе (36,16 МГц) 
Таблица 1. ЭСХ бентонитовых глин Таганского месторождения, механоактивированных в течение 120 с с различным количеством модифицирующей добавки

\begin{tabular}{|c|c|c|c|c|c|c|}
\hline $\begin{array}{c}\text { Концентрация } \\
\text { мусковита, \% }\end{array}$ & $\begin{array}{c}\text { Время } \\
\text { отстоя } \\
\text { образца, ч }\end{array}$ & $\begin{array}{c}\text { Дзета- } \\
\text { потенциал, } \\
\text { mV }\end{array}$ & $\begin{array}{c}\text { Поверхностный } \\
\text { заряд, } 10^{-6} \mathrm{mV}\end{array}$ & $\begin{array}{l}\text { Диаметр } \\
\text { д.э.с., nm }\end{array}$ & $\begin{array}{c}\text { Микро- } \\
\text { вязкость, } \\
\text { micron/ } \\
\text { sec/V/Cm }\end{array}$ & $\begin{array}{c}\text { Частота } \\
\text { Максвелла- } \\
\text { Вагнера, } \\
\text { МГц }\end{array}$ \\
\hline \multirow{2}{*}{0} & 0 & 20,11 & 0,297 & 4,03 & 1,78 & 18,92 \\
\hline & 24 & 28,32 & 0,638 & 3,22 & 3,02 & 23,91 \\
\hline \multirow{2}{*}{1} & 0 & 20,13 & 0,295 & 4,02 & 1,78 & 18,99 \\
\hline & 24 & 28,42 & 0,640 & 3,23 & 3,05 & 23,91 \\
\hline \multirow{2}{*}{2} & 0 & 20,31 & 0,299 & 4,04 & 1,78 & 19,23 \\
\hline & 24 & 28,98 & 0,640 & 3,23 & 3,07 & 26,93 \\
\hline \multirow{2}{*}{3} & 0 & 21,87 & 0,301 & 4,03 & 1,80 & 21,15 \\
\hline & 24 & 29,56 & 0,642 & 3,22 & 3,11 & 29,07 \\
\hline \multirow{2}{*}{4} & 0 & 23,93 & 0,303 & $\underline{4,00}$ & 1,87 & 23,92 \\
\hline & 24 & 30,05 & $\underline{0,644}$ & 3,22 & $\underline{3,20}$ & $\underline{36,16}$ \\
\hline \multirow{2}{*}{5} & 0 & 23,97 & $\underline{0,305}$ & 4,00 & 1,92 & 23,14 \\
\hline & 24 & $\underline{\underline{30,36}}$ & 0,644 & $\underline{\underline{3,21}}$ & 3,20 & 35,98 \\
\hline \multirow{2}{*}{6} & 0 & 24,01 & 0,305 & 4,02 & $\underline{1,94}$ & 22,19 \\
\hline & 24 & 15,87 & 0,644 & 3,21 & 1,21 & 34,99 \\
\hline
\end{tabular}

Примечание: *24,01 - максимальное значение для суспензий без отстоя (измерения проводили сразу после затворения

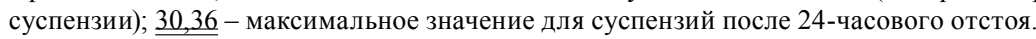

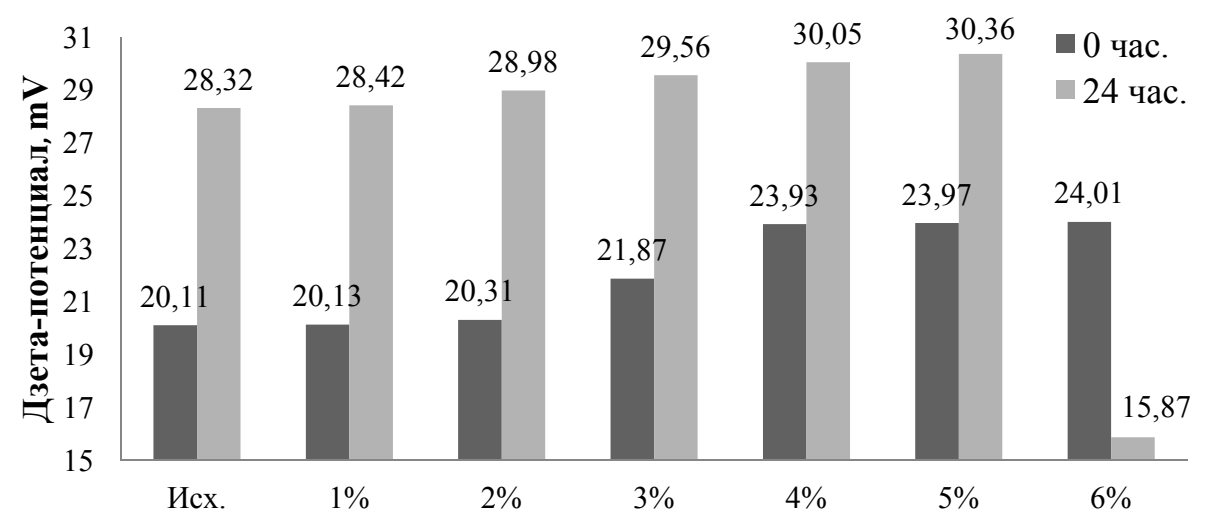

Рис. 1. Дзета-потенциал механоактивированных (120 с) глин Таганского месторождения при различном количестве модифицирующей добавки в виде мусковита (1-6 \%)

и до 34,99 МГц с 6 \% мусковита соответственно. Данный процесс происходит при стабильно неизменном диаметре двойного электрического слоя, который в данном случае составил 3,213,22 нм, что в сумме приводит к нарушению баланса сил притяжения и отталкивания и, как следствие, к агломерации и уменьшению дзета-потенциала.

Микровязкость для глин Таганского месторождения достигла максимальных значений при активации материала в течение 120 с с 4 \% механоактивированного мусковита, она равнялась 


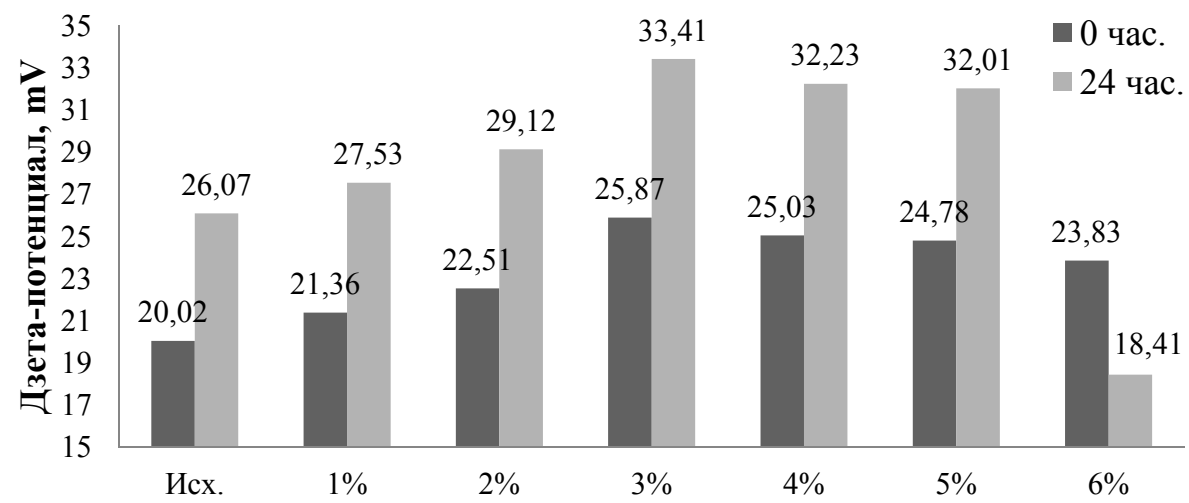

Рис. 2. Дзета-потенциал механоактивированных (90 с) глин Черногорского месторождения при различном количестве модифицирующей добавки в виде мусковита (1-6 \%)

Таблица 2. ЭСХ бентонитовых глин Черногорского месторождения? механоактивированных в течение 90 с с различным количеством модифицирующей добавки

\begin{tabular}{|c|c|c|c|c|c|c|}
\hline $\begin{array}{l}\text { Концентрация } \\
\text { муско-вита, \% }\end{array}$ & $\begin{array}{c}\text { Время } \\
\text { отстоя } \\
\text { образца, ч }\end{array}$ & $\begin{array}{c}\text { Дзета- } \\
\text { потенциал, } \\
\text { mV }\end{array}$ & $\begin{array}{c}\text { Поверхностный } \\
\text { заряд, } 10^{-6} \mathrm{mV}\end{array}$ & $\begin{array}{l}\text { Диаметр } \\
\text { д.э.с., nm }\end{array}$ & $\begin{array}{c}\text { Микро- } \\
\text { вязкость, } \\
\text { micron/ } \\
\text { sec/V/Cm }\end{array}$ & $\begin{array}{c}\text { Частота } \\
\text { Максвелла- } \\
\text { Вагнера, } \\
\text { МГц }\end{array}$ \\
\hline \multirow{2}{*}{0} & 0 & 20,02 & 0,408 & 4,61 & 1,74 & 29,12 \\
\hline & 24 & 26,07 & 0,819 & 3,92 & 2,96 & 33,45 \\
\hline \multirow{2}{*}{1} & 0 & 21,36 & 0,408 & 4,61 & 1,76 & 32,56 \\
\hline & 24 & 27,53 & 0,819 & 3,91 & 2,97 & 35,96 \\
\hline \multirow{2}{*}{2} & 0 & 22,51 & 0,409 & 4,60 & $\underline{1,79}$ & 34,47 \\
\hline & 24 & 29,12 & 0,820 & 3,91 & 2,98 & 39,34 \\
\hline \multirow{2}{*}{3} & 0 & 25,87 & 0,411 & 4,60 & 1,79 & $\underline{39,83}$ \\
\hline & 24 & 33,41 & 0,823 & 3,91 & 2,99 & $\underline{42,53}$ \\
\hline \multirow{2}{*}{4} & 0 & 25,03 & 0,415 & 4,60 & 1,78 & 38,74 \\
\hline & 24 & 32,23 & 0,823 & $\underline{3,92}$ & $\underline{3,02}$ & 42,50 \\
\hline \multirow{2}{*}{5} & 0 & 24,78 & 0,417 & $\underline{4,59}$ & 1,78 & 38,15 \\
\hline & 24 & 32,01 & 0,824 & 3,92 & 3,01 & 42,49 \\
\hline \multirow{2}{*}{6} & 0 & 23,83 & $\underline{0,419}$ & 4,59 & 1,77 & 37,27 \\
\hline & 24 & 18,41 & 0,825 & 3,92 & 1,11 & 26,14 \\
\hline
\end{tabular}

Примечание: *25,87- максимальное значение для суспензий без отстоя (измерения проводили сразу после затворения суспензии); $\underline{33,41}$ - максимальное значение для суспензий после 24-часового отстоя.

1,87 и 3,20 micron/sec/V/Cm для суспензии без отстоя и с отстоем соответственно. В табл. 1 для суспензии без отстоя присутствуют данные микровязкости, составляющие $1,94 \mathrm{micron} / \mathrm{sec} / \mathrm{V} /$ $\mathrm{Cm}$, но данным результатом можно пренебречь, потому как после отстоя это значение будет равным уже лишь 1,21 .

Из данных табл. 2 видно, что значения всех характеристик суспензии после 24-часового отстоя увеличиваются. Дзета-потенциал с увеличением времени активации материала увели- 
чивается с 20,02 до 25,87 мВ для суспензий без отстоя и с 26,07 до 33,41 мВ для суспензий с 24-часовым отстоем.

Максимальное значение дзета-потенциала соответствует времени механоактивации глинистого материала в течение $90 \mathrm{c}$, последующая механоактивация приводит к уменьшению данной характеристики до 18,41 мВ. Общая поляризованность системы оценивалась максвеллвагнеровской частотой, максимальные значения которой приняла глина, механоактивированная 90 с, с 3 \% механоактивированного мусковита и составила 39,83 (без отстоя) и 42,53 МГц (с 24-часовым отстоем). Микровязкость достигла максимальных значений при активации материала в течение 90 с, с 4 \% механоактивированного мусковита она составила 1,78 и 3,02 micron/ $\mathrm{sec} / \mathrm{V} / \mathrm{Cm}$ для суспензии без отстоя и с отстоем соответственно.

\section{Исследование стабильности противопригарных покрытий для литья в ПГС с модифицированным мусковитом механоактивированных бентонитовых глин}

В современном мире уже давно обозначилась тенденция к улучшению качества получаемой продукции во всех сферах промышленности, поэтому при высоком выпуске чугунной и стальной продукции необходимо соблюдать качество получаемых изделий, минимизируя такие основные дефекты, как пригар, наросты, раковины, ужимины, недоливы и другие, а также оптимизировать не только труд работников, но и расход и использование основных материалов в производстве, поскольку это не только несет выгоду в экономическом смысле, но и повышает качество готовой продукции.

Противопригарные покрытия являются наиболее эффективным средством для получения отливок без пригара и дефектов. При их нанесении на поверхность форм и стержней создается буферный защитный слой с заданными физико-механическими свойствами. При правильном выборе и применении покрытий достигается значительное улучшение качества поверхности получаемых отливок, товарный вид и в итоге их конкурентоспособность.

Предлагается применять противопригарное покрытие марки ГБ-3, которое включает в себя основное сырье и материалы, используемые в литейном производстве, - это графит Курейского месторождения марки ГЛС-2 как основной материал покрытия и глина Таганского месторождения марки БП1Т1; глина Таганского месторождения, механоактивированная 120 с; глина Таганского месторождения, механоактивированная 120 с, модифицированная мусковитом в количестве 5 \%; глина Черногорского месторождения марки БП1Т1; глина Черногорского месторождения, механоактивированная 90 c; глина Черногорского месторождения, механоактивированная 90 с, модифицированная мусковитом в количестве $3 \%$. Выбор глин был произведен в соответствии с результатами, полученными на водно-глинистых суспензиях с максимальными электростатическими характеристиками для них. Состав противопригарного покрытия представлен в табл. 3.

Ожидаемым результатом исследования является повышение технологических свойств, а именно седиментационной и агрегативной устойчивости противопригарных покрытий путем применения в их составе механоактивированных и модифицированных мусковитом бентонитовых глинистых минералов, которые при взаимодействии с растворителем имеют повышенные электростатические характеристики суспензий на их основе. 
В процессе приготовления и испытаний установлено, что использование механоактивированного бентонита и механоактивированного модифицированного мусковитом бентонита способствует увеличению расхода воды и повышению вязкости покрытия (табл. 4). Эта закономерность верна как для глин Таганского, так и для глин Черногорского месторождения. Это можно объяснить тем, что бентонитовые частицы становятся более активными, способны притягивать к себе больше молекул воды, в результате увеличивается структурная вязкость.

В табл. 4 представлен расход воды на противопригарные покрытия с различными модифицирующими слоистыми добавками и их вязкость. Рабочая плотность всех покрытий 1,4 г/см³. Из данных таблицы видно, что механоактивация способствует увеличению расхода воды при приготовлении противопригарного покрытия. Исключением является таганская глина (MА $120)+4 \%$ мусковита, расход воды которой увеличивается на $12,5 \%$ по сравнению с исходной глиной и уменьшается на 25 \% по сравнению с глиной, активированной при 120 с без модифицирующей добавки.

Структурную вязкость суспензий оценивают через поверхностное натяжение и коллоидальность. Эти характеристики обусловливают устойчивость суспензий к расслоению во времени и при одинаковой природе материалов и зависят от дисперсности и энергетических параметров частиц. Измерение вязкости покрытий определяли на вискозиметре В3-4 (ГОСТ 8420-74). Повышение структурной вязкости влечет за собой улучшение качества покрытия по одному из важнейших технологических свойств - седиментационной устойчивости (ГОСТ 10772-78). В табл. 5 отражены результаты седиментационной устойчивости: 1, 3, 7, 24 ч.

Из данных табл. 5 видно, что седиментационная устойчивость у противопригарных покрытий с добавлением таганской глины выше, чем у красок с черногорской глиной в исходных

Таблица 3. Компонентный состав краски ГБ-3 для чугунного литья

\begin{tabular}{|c|c|c|c|c|c|c|c|c|c|}
\hline \multirow[b]{2}{*}{ Марка } & \multicolumn{8}{|c|}{ Состав пасты, \% по массе } & \multirow{2}{*}{$\begin{array}{c}\text { Плотность } \\
\text { краски, } \\
\text { разведенной } \\
\text { водой, г/см }\end{array}$} \\
\hline & графит & кварц & тальк & бентонит & 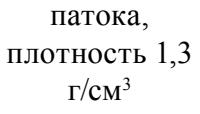 & формалин & вода & ЛСТ & \\
\hline ГБ-3 & 58,5 & - & - & 3,5 & - & - & 28 & 10 & 1,40 \\
\hline
\end{tabular}

Таблица 4. Вязкость противопригарных покрытий ГБ-3

\begin{tabular}{|l|c|c|}
\hline \multicolumn{1}{|c|}{ Глина } & Вода, мл & Вязкость, с \\
\hline 1. Таганская исх. & 80 & 40 \\
\hline 2. Таганская (МА120) & 120 & 50 \\
\hline 3. Таганская (МА120+5 \% МА мусковита) & 90 & 75 \\
\hline 4. Черногорская исх. & 110 & 32 \\
\hline 5. Черногорская (МА 90) & 130 & 48 \\
\hline 6. Черногорская (МА 90+3 \% МА мусковита) & 145 & 70 \\
\hline
\end{tabular}


Таблица 5. Седиментационная устойчивость покрытий ГБ-3

\begin{tabular}{|l|c|c|c|c|}
\hline \multirow{2}{*}{ Материал } & \multicolumn{4}{|c|}{ Время седиментации, ч } \\
\cline { 2 - 6 } & 1 & 3 & 7 & 24 \\
\hline Таганская исх. & 91 & 88 & 82 & 72 \\
\hline Таганская (МА120) & 97 & 95 & 91 & 88 \\
\hline Таганская (МА120 + 5 \% МА мусковита) & 100 & 99 & 99 & 97 \\
\hline Черногорская исх. & 79 & 73 & 62 & 50 \\
\hline Черногорская (МА 90) & 89 & 84 & 74 & 69 \\
\hline Черногорская (МА 90+3 \% МА мусковита) & 100 & 98 & 97 & 96 \\
\hline
\end{tabular}

состояниях, так как это связано с качеством исследуемого материала, а именно с количеством минерала монтмориллонита в химическом составе глин.

Механоактивация глин позволяет увеличить седиментационную устойчивость обеих исследуемых глин. Прирост седиментационной устойчивости у глин Таганского месторождения, механоактивированных 120 с, составляет 6 ед., у глин Черногорского месторождения, механоактивированных 90 с, прирост равен 10 ед., но высокая доля монтмориллонита в составе высокосортной глины Таганского месторождения не позволяет показать механоактивированной глине Черногорского месторождения результаты, сопоставимые даже с исходной таганской глиной без механоактивации.

После добавления модифицирующей добавки в виде мусковита в механоактивированные глины Таганского и Черногорского месторождений результаты седиментационной устойчивости противопригарных покрытий ГБ-3 (о чем свидетельствовал и дзета-потенциал водноглинистых суспензий) вырастают до стабильно высоких значений, которые даже после 24-часового отстоя не снизились менее 96 ед. Седиментационная устойчивость противопригарного покрытия ГБ-3 с механоактивированными и модифицированными мусковитом бентонитовыми глинами в течение времени представлена на рис. 3.

Механоактивация глин с измельчением фракционного состава приводит к повышению энергетики частиц материала под воздействием модифицирующих добавок с увеличением общей активности глинопорошков. Этот процесс позволяет получать сбалансированную коллоидную систему, состоящую из необходимо заряженных потенциалообразующих частиц. Так как в литейном производстве глина в основном применяется в состоянии суспензии или близком к нему, то назревает необходимость исследования исходных глин и глинопорошков с изучением процессов влияния и воздействия на основные параметры.

\section{Выводы}

1. Определено влияние различного количества мусковита в составе бентонитовых глин, применяемых в литейном производстве, на электростатические характеристики водных суспензий на их основе. Введение 3 \% механоактивированного мусковита в механоактивированную 90 с бентонитовую глину Черногорского месторождения позволило увеличить дзетапотенциал на 30 \%, до значения 25,87 мВ, для суспензий сразу после затворения и на 28 \% (33,41 мВ) для суспензий после 24-часового отстоя. Общий эффект от комплекса мер (механоактива-

$$
-940-
$$




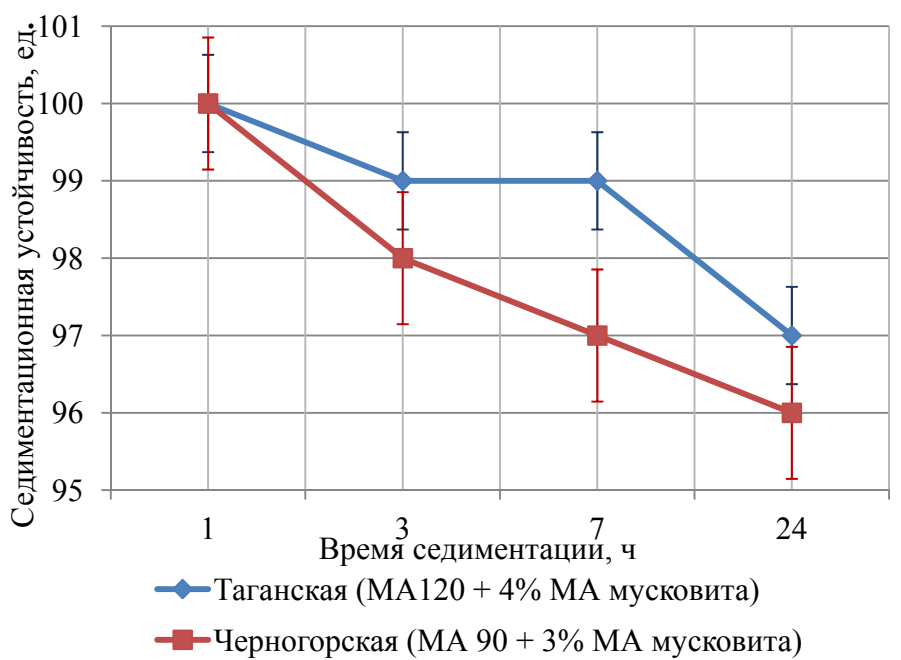

Рис. 3. Седиментационная устойчивость противопригарного покрытия ГБ-3 с механоактивированными и модифицированными мусковитом бентонитовыми глинами различных месторождений

ция и модифицирование) составил: увеличение с 9,37 до 25,87 мВ для суспензий без отстоя и с 14,01 до 33,41 мВ для суспензий после 24-часового отстоя.

2. Выявлено, что введение 5 \% механоактивированного мусковита в механоактивированную 120 с бентонитовую глину Таганского месторождения позволило увеличить дзетапотенциал на $14,9 \%$, до значения 23,97 мВ, для суспензий сразу после затворения и на 7 \% (30,36 мВ) для суспензий после 24-часового отстоя. Общий эффект от комплекса мер (механоактивация и модифицирование) составил: увеличение с 11,53 до 23,97 мВ для суспензий без отстоя и с 16,11 до 30,36 мВ для суспензий после 24-часового отстоя.

3. Определено, что механоактивация является наиболее эффективным и универсальным способом повышения стабильности бентонитовых суспензий, применяемых в составах ПГС и противопригарных покрытий, но имеет свои пределы, после которых дальнейшая механоактивация приносит отрицательный эффект - агломерацию частиц глинистого минерала, что сводит на нет все предшествующие усилия по повышению стабильности системы «вода - глина». Механоактивацией не всегда можно добиться ожидаемых результатов из-за ее пределов, поэтому модифицирование бентонитовых глин другими минералами служит оправданной и эффективной мерой для получения высоких показателей стабильности суспензий. В частности, повышение на 30 \% для черногорской и на 14,9 \% для таганской глин сверх значений после механоактивации весомо, так как дзета-потенциал «переваливает» за $30 \mathrm{mB}$, что служит характеристикой устойчивой коллоидной системы, до 30 мВ возможна агломерация, коагуляция или флокуляция частиц исследуемого материала [8].

4. Установлено, что механоактивированная глина, модифицированная мусковитом, способствует увеличению вязкости противопригарных покрытий на основе графита. По сравнению с исходными глинами Таганского и Черногорского месторождений вязкость увеличивается почти в два раза.

$$
-941-
$$


5. Выявлено, что глина, механоактивированная и модифицированная мусковитом, способствует увеличению седиментационной и агрегативной устойчивости противопригарных покрытий, а именно после 24-часового отстоя седиментационная устойчивость не опустилась ниже 96 ед. Для глин Таганского месторождения увеличение седиментационной устойчивости составило: после 1 ч - 9,8 \%; 3 ч -12,5 \%; 7 ч - 20,7 \%; 24 ч - 34,7 \% по сравнению с исходными образцами глины, широко применяемыми в литейном производстве вследствие доступности, дешевизны и относительно стабильных показателей свойств.

6. Определено, что седиментационная устойчивость противопригарных покрытий, в составе которых находилась глина, механоактивированная и модифицированная мусковитом, увеличилась на 26,5 \% после 1 ч отстоя, на 34,2 \% после 3 ч, на 56,45 \% после 7 ч, на 92 \% после 24 ч. Мусковит в количестве 3 \% в механоактивированной глине Черногорского месторождения позволил увеличить седиментационную устойчивость противопригарных покрытий до значений, сопоставимых с высокосортными глинами Таганского месторождения (рис. 3), что является положительным моментом для экономики Красноярского края и близлежащих федеральных округов РФ, поскольку Черногорское месторождение местное и расположено близко к предприятиям черной и цветной металлургии.

\section{Список литературы}

[1] Трофимова Ф.А., Тетерин А.Н. Возможности получения кондиционных глинопорошков и бентонитоподбных глин республики Татарстан. Тезисы докладов Международной научной конференции «Глины и глинистые минераль»». Воронеж, 2004, $37-38$ [Trofimova F.A., Teterin A.N. Opportunities for conditional drill mud and clay bentonitopodbnyh Tatarstan republic. Abstracts of the International Scientific Conference "Clays and clay minerals." Voronezh, 2004, 3738 (in Russian)].

[2] Беляев С.В., Лесив Е.М., Юрьев П.О. Исследование изменения электростатических характеристик бентонитовых глин Таганского месторождения от режимов механоактивации . Цветные металлы и минералы: Сб. тезисов и докладов VI межд. конгресса, 15-18 сентября 2014 г. Красноярск: Версо, 2014. 940-945 [Belyaev S.V., Lesiv E.M., Yuryev P.O. Research of change of electrostatic characteristics of bentonite clay deposits from Tagansky mechanical activation modes. Non-ferrous metals and minerals: Sat. theses and reports VI Int. Congress, 15-18 September 2014, Krasnoyarsk: Verso, 2014. 940-945 (in Russian)].

[3] Belyaev S.V., Yuryev P.O. Research change of electrostatic characteristics of the bentonite clays from various modes mekhanoaktivivation. Australian Journal of Scientific Research. 2014. 1(5). 510-518.

[4] Худоногов С.А., Богданова Т.А., Гильманшина Т.Р. [и др.]. Исследование свойств суспензий на основе углеродсодержащих материалов для литейного производства. Цветные металлы и минералы 2015: Сб. тезисов докладов VI межд. конгресса, г. Красноярск, 15-18 сентября 2015 г. Красноярск: Версо, 2015. 1196-1197 [Khudonogov S.A., Bogdanova T.A., Gilmanshina T.R. [etc.]. Investigation of properties of suspensions based on carbonaceous materials for foundry production. Non-Ferrous Metals and Minerals 2015: Sat. Abstracts of VI int. Congress, Krasnoyarsk, 15-18 September 2015, Krasnoyarsk: Verso, 2015. 1196-1197 (in Russian)]. 
[5] Овчинников П.Ф., Круглицкий Н.Н., Михайлов Н.В. Реология тиксотропных систем. Киев: Наукова думка, 1972. 120 с [Ovchinnikov P.F., Kruglitsky N.N., Mikhailov N.V. Thixotropic rheology systems. Naukova Dumka, 1972. 120 p (in Russian)]

[6] Смолко В.А., Антошкина Е.Г. Электрофизические методы активации водных суспензий глинистых минералов. Вестник ЮУрГУ. Серия «Металлургия», 2014. 14(1), $24-27$ [Smolko V.A., Antoshkina E.G. Electrophysical methods of activation aqueous suspensions of clay minerals. Bulletin of South Ural State University. “Metallurgy” Series, 2014. 14 (1), 24-27 (in Russian)]. 